\title{
miR-125b controls apoptosis and temozolomide resistance by targeting TNFAIP3 and NKIRAS2 in glioblastomas
}

\author{
S Haemmig ${ }^{1}$, U Baumgartner ${ }^{1}$, A Glück ${ }^{1,3}$, S Zbinden ${ }^{1}$, MP Tschan ${ }^{1}$, A Kappeler ${ }^{1}$, L Mariani ${ }^{2}$, I Vajtai ${ }^{1}$ and E Vassella ${ }^{*, 1}$
}

Diffusely infiltrating gliomas are among the most prognostically discouraging neoplasia in human. Temozolomide (TMZ) in combination with radiotherapy is currently used for the treatment of glioblastoma (GBM) patients, but less than half of the patients respond to therapy and chemoresistance develops rapidly. Epigenetic silencing of the $0^{6}$-methylguanine-DNA methyltransferase (MGMT) has been associated with longer survival in GBM patients treated with TMZ, but nuclear factor $\kappa B$ (NF- $\kappa$ B)-mediated survival signaling and TP53 mutations contribute significantly to TMZ resistance. Enhanced NF- $\kappa$ B is in part owing to downregulation of negative regulators of NF- $\kappa$ B activity, including Tumor necrosis factor alpha-induced protein 3 (TNFAIP3) and NF- $\kappa$ B inhibitor interacting RAS-like 2 (NKIRAS2). Here we provide a novel mechanism independent of TP53 and MGMT by which oncogenic miR-125b confers TMZ resistance by targeting TNFAIP3 and NKIRAS2. GBM cells overexpressing miR-125b showed increased NF- $\kappa$ B activity and upregulation of anti-apoptotic and cell cycle genes. This was significantly associated with resistance of GBM cells to TNF $\alpha$ - and TNF-related inducing ligand-induced apoptosis as well as resistance to TMZ. Conversely, overexpression of anti-miR-125b resulted in cell cycle arrest, increased apoptosis and increased sensitivity to TMZ, indicating that endogenous miR-125b is sufficient to control these processes. GBM cells overexpressing TNFAIP3 and NKIRAS2 were refractory to miR-125b-induced apoptosis resistance as well as TMZ resistance, indicating that both genes are relevant targets of miR-125b. In GBM tissues, high miR-125b expression was significantly correlated with nuclear NF- $\kappa B$ confirming that miR-125b is implicated in NF- $\kappa$ B signaling. Most remarkably, miR-125b overexpression was clearly associated with shorter overall survival of patients treated with TMZ, suggesting that this microRNA is an important predictor of response to therapy.

Cell Death and Disease (2014) 5, e1279; doi:10.1038/cddis.2014.245; published online 5 June 2014

Subject Category: Cancer

\section{Introduction}

Gliomas, which account for at least $60 \%$ of primary brain tumors in adults, are among the prognostically most discouraging neoplasia in human. Depending on an individual constellation of clinical variables and histological parameters, median survival of patients ranges from some months to 12-15 years. ${ }^{1}$ Glioblastoma multiforme (GBM) represents the highest grade (WHO grade IV) within the prevailing astrocytic category of tumors, and present either as a de novo neoplasm (primary GBM) or as the endpoint of tumor progression from a lower grade precursor (secondary GBM). With optimal treatment, the mean survival time of patients with GBM is $<15$ months.

Surgical resection of GBM is essentially palliative as the tumor infallibly recurs because of its pervasively infiltrative growth. ${ }^{2}$ Patients receiving a combination of radio- and chemotherapy using the alkylating agent temozolomide (TMZ) tend to have a significantly longer overall and progression-free survival, but not all patients benefit from therapy and resistance develops rapidly in those patients. ${ }^{1,3}$
$\mathrm{O}^{6}$-methylguanine-DNA methyltransferase (MGMT) promoter methylation $^{2,4,5}$ and mutations in the isocitrate dehydrogenase (IDH) subunits IDH1 and IDH2 $2^{6,7}$ correlate with a higher rate of objective response to TMZ.

Constitutive activity of nuclear factor $\kappa \mathrm{B}(\mathrm{NF}-\kappa \mathrm{B})$ signaling, which occur in up to $90 \%$ of GBMs, is an important regulator of proliferation, invasion and apoptosis. ${ }^{8,9} \mathrm{NF}-\kappa \mathrm{B}$ is one of the major factors modulating the ability of cancer cells to resist apoptosis and to contribute to chemoresistance. ${ }^{10,11} \mathrm{NF}-\kappa \mathrm{B}$ comprises two subunits, commonly p50 (NFKB1)/p65 (RelA), which in its inactive state is held in the cytoplasm by the inhibitor of NF- $\kappa \mathrm{B}\left(\mathrm{I}_{\kappa} \mathrm{B}\right) . \mathrm{I}_{\kappa} \mathrm{B}$ is regulated by $\mathrm{I}_{\kappa} \mathrm{B}$ kinase (IKK): upon stimulation by external signals or stress, IKK is activated and phosphorylates $I_{\kappa} \mathrm{B}$ and, thereby, targets $\mathrm{I}_{\kappa} \mathrm{B}$ to ubiquitinmediated protein degradation. As a result, NF- $\kappa$ B is released and translocates into the nucleus where it transactivates multiple genes involved in proliferation, invasion and apoptosis (reviewed by Nakanishi and Toi ${ }^{11}$ ).

Little information is available on the mechanism that may account for constitutive activity of NF- $\kappa \mathrm{B}$ in gliomas. Tumor

${ }^{1}$ Institut für Pathologie, University of Bern, Bern, Switzerland and ${ }^{2}$ Klinik und Poliklinik, University Hospital Basel, Basel, Switzerland

${ }^{*}$ Corresponding author: E Vassella, Institut für Pathologie, University of Bern, Murtenstrasse 31, Bern CH-3010, Switzerland. Tel: +41 316329943 ; Fax: +41 31381 8764; E-mail: erik.vassella@pathology.unibe.ch

${ }^{3}$ Present address: Departement Klinische Forschung, Bern, Switzerland

Abbreviations: GBM, glioblastoma multiforme; IDH, isocitrate dehydrogenase; $I_{\kappa} \mathrm{B}$, inhibitor of $\kappa \mathrm{B}$; MGMT, $0^{6}$-methylguanine-DNA methyltransferase; miRNA, microRNA; NF- $\kappa$ B, nuclear factor $\kappa \mathrm{B}$; NKIRAS2, NF- $\kappa$ B inhibitor interacting RAS-like 2; TMZ, temozolomide; TNFAIP3, Tumor necrosis factor alpha-induced protein 3; TRAIL, TNF-related inducing ligand

Received 11.3.14; revised 28.3.14; accepted 29.4.14; Edited by G Calin 
necrosis factor alpha-induced protein 3 (TNFAIP3, also known as A20), which acts in a negative feedback loop to block NF- $\kappa \mathrm{B}$ activity and is significantly associated with resistance to $\mathrm{TMZ}$, is frequently downregulated in $\mathrm{GBM}{ }^{12}$ TNFAIP3 catalyzes the cleavage of K63-linked ubiquitin chains and the conjugation of K48-linked polyubiquitin chains, thereby targeting receptor-interacting serine-threonine kinase 1 for degradation. ${ }^{13,14}$ Other negative regulators including NF$\kappa \mathrm{B}$ inhibitor interacting RAS-like (NKIRAS) 1 and 2, which interfere with proteosomal degradation of $I_{\kappa} \mathrm{B}$, have also been implicated in regulating NF- $\kappa \mathrm{B}$ activity, ${ }^{15-18}$ but their role in gliomas is poorly understood. In addition, the molecular mechanism of downregulation of these negative regulatory proteins in gliomas remains largely unknown.

In this study, we tested the hypothesis, whereby microRNAs (miRNAs), short regulatory sequences that control gene expression at the posttranscriptional level, would be implicated in the regulation of $\mathrm{NF}-\kappa \mathrm{B}$ activity in gliomas. miRNAs are incorporated into RNA-induced silencing complex where they bind to target mRNAs and, depending on the degree of complementarity to their target sequence, confer mRNA degradation and/or translation inhibition of the target gene (reviewed by lorio and $\mathrm{Croce}^{19}$ ). miRNAs are involved in the regulation of most basic cellular processes and are also implicated in tumorigenesis where they act as oncogenic or tumor suppressing miRNAs (reviewed by Hwang and Mendel ${ }^{20}$ ).

Here we show that miR-125b, a brain-enriched miRNA, is implicated in the regulation of $N F-\kappa B$ activity in GBM by targeting TNFAIP3 and NKIRAS2. We show for the first time that, owing to downregulation of these targets, miR-125b controls proliferation and apoptosis, and confers TMZ resistance of GBM cell lines in a MGMT- and TP53independent manner. These results can be extrapolated to clinical cases of GBM, as miR-125b expression significantly correlates with nuclear NF- $\kappa \mathrm{B}$ in surgically obtained GBM samples indicated that miR-125b is directly implicated in TMZ resistance.

\section{Results}

miR-125a/b directly target TNFAIP3 and NKIRAS2 in GBM cell lines. To identify miRNAs that are able to induce $\mathrm{NF}-\kappa \mathrm{B}$ signaling, we searched target prediction databases for putative target genes implicated in negative regulation of $N F-\kappa B$ using miRNAs that are overexpressed in GBM tissues. $^{21}$ Target prediction algorithms using target scan (www.targetscan.org), miRDB (http://mirdb.org) or DianaLab (http://diana.cslab.ece.ntua.gr) revealed that TNFAIP3 and NKIRAS2 are putative targets of oncogenic miR-125a and $\mathrm{miR}-125 \mathrm{~b}$. miR-125a/b binding sites of eight nucleotides in length were detected in the $3^{\prime}$ UTR of each gene and in the coding region of TNFAIP3 (Supplementary Figure S1A). To assess direct regulation by $m i R-125 a / b$, luciferase constructs containing predicted miR-125a/b binding sites from the 3' UTR of the respective genes were cloned downstream of the luciferase reporter gene (Supplementary Figure S1B). U87 or LN-18 GBM cell lines, transiently transfected with miR-125a/b precursors, displayed significantly lower luciferase activity for reporter constructs containing the binding site for
TNFAIP3 or NKIRAS2 relative to the control construct containing no binding site (Figures $1 \mathrm{a}$ and $\mathrm{b}$ ). In contrast, downregulation of luciferase activity was abrogated in constructs in which the miR-125a/b binding site was mutated (Figures $1 \mathrm{a}$ and $\mathrm{b}$ and Supplementary Figure S1B). Consistent with these findings, the TNFAIP3 and NKIRAS2 mRNA levels were significantly reduced in U87 or $\mathrm{LN}-18$ cells that were transiently transfected with $\mathrm{miR}-125 \mathrm{a} / \mathrm{b}$ precursors (Figure 2a). In addition, the TNFAIP3 mRNA level was inversely correlated with the level of miR-125b in 452 GBM samples from the Cancer Genome Atlas (TCGA) database (Supplementary Table S1). Under the same conditions, TNFAIP3 and NKIRAS2 proteins were strongly reduced (Figure $2 \mathrm{~b}$ ). These results clearly indicate that $\mathrm{miR}-125 \mathrm{a} / \mathrm{b}$ directly target TNFAIP3 and NKIRAS2.

Endogenous miR-125b is sufficient to regulate TNFAIP3 and NKIRAS2. Luciferase activity of the reporter construct containing the target site of TNFAIP3 was almost maximally reduced by endogenous miR-125a/b (Figure 1a, precursor control). In contrast, transfection of GBM cells with $\mathrm{miR}-125 \mathrm{a} / \mathrm{b}$ precursor did not lead to a further reduction in luciferase activity (Figure 1a). To confirm that endogenous miR-125b is sufficient to downregulate TNFAIP3 and NKIRAS2, GBM cell lines were transduced with a lentiviral
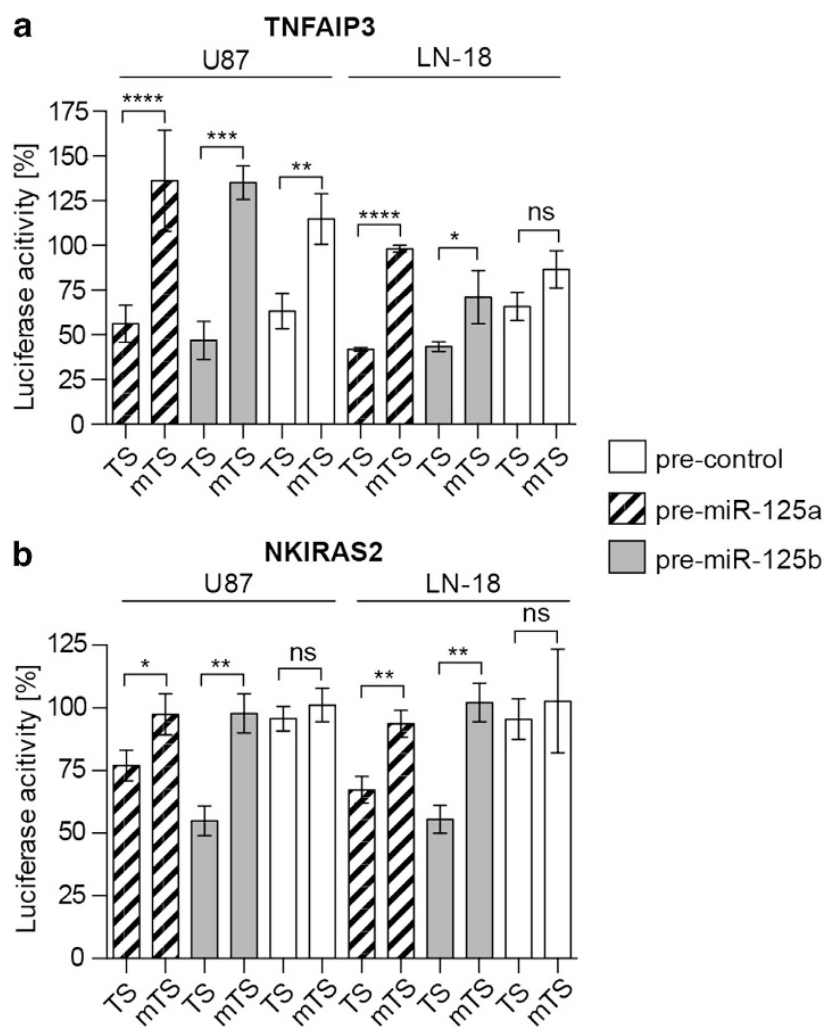

Figure $1 \mathrm{miR}-125 \mathrm{a}$ and miR-125b directly target TNFAIP3 and NKIRAS2 in GBM cells. Luciferase constructs containing the wild-type (TS) or mutated (mTS) miR-125a/b target site from TNFAIP3 or NKIRAS2 were co-transfected with pre-miR-125a/b or pre-control into GBM cells. Luciferase activity is presented for TNFAIP3 (a) and NKIRAS2 (b) relative to the activity obtained with the construct Luc containing no target site $(n=3)$ 
vector expressing antisense miR-125b giving rise to fivetimes lower levels of miR-125b (Figure 2c). Indeed, anti-miR125b elicited a 2-2.5-fold increase in the mRNA level (Figure 2c) and an increase, up to fivefold, in the protein level (Figure 2d) of TNFAIP3 and NKIRAS2. In contrast, antimiR-125a was barely able to affect the mRNA or protein level of TNFAIP3 or NKIRAS2 (data not shown) suggesting that miR-125b is the relevant miRNA. In agreement with this finding, the level of miR-125b was up to 20 times higher than that of miR-125a in both GBM cell lines and GBM tissues (Supplementary Figure S2). Hence, we focused on miR-125b in subsequent experiments.

miR-125b is implicated in the regulation of $\mathrm{NF}-\kappa \mathrm{B}$ activity. To assess whether miR-125b is able to induce $\mathrm{NF}-\kappa \mathrm{B}$ activity, reporter assays were performed using a construct containing the luciferase gene under the control of a NF- $\kappa \mathrm{B}$-inducible promoter. miR-125b precursor elicited a twofold higher luciferase activity in U87, LN-18 and U251 GBM cells compared with scrambled control (pre-control) (Figure $3 a$ and Supplementary Figure S3). Consistent with these findings, blocking endogenous miR-125b by antisense miR-125b resulted in reduced luciferase activity of U87 cells (Figure 3a). Luciferase activity was barely detectable in LN-18 cells overexpressing anti-miR-125b (data not shown). However, results consistent with those for U87 cells were obtained, when LN-18 cells were treated with $\operatorname{TNF} \alpha$, an inducer of NF- $\kappa \mathrm{B}$ activity (compare Figures $3 a$ and $b$ ).

To confirm NF- $\kappa \mathrm{B}$ activation using an independent approach, nuclear and cytoplasmic fractions of cells cultured in the presence or absence of TNF $\alpha$ were analyzed by western blotting. The level of nuclear p65 was higher in cells transfected with pre-miR-125b relative to cells transfected with pre-control irrespective of whether they were cultured in the presence of absence of TNF $\alpha$ (Figure 3c). Complementary results were obtained for cytoplasmic fractions giving rise to reduced p65 levels in cells overexpressing miR-125b (Figure $3 \mathrm{~d}$ ). In addition, miR-125b conferred prolonged $\mathrm{I}_{\kappa} \mathrm{B}$ phosphorylation and concomitantly enhanced $\mathrm{I} \kappa \mathrm{B}$ degradation (Figure $3 d$ ) consistent with a concept that negative feedback loops mediated by TNFAIP3 and NKIRAS2 are abrogated in cells overexpressing miR-125b.

$\mathrm{NF}-\kappa \mathrm{B}$ is a transcriptional activator of anti-apoptotic and proliferative genes. ${ }^{22}$ Transient transfection with miR-125b precursor gave rise to increased levels of anti-apoptotic genes $B C l-2$ (Figure $4 a$ ) and $c-I A P 2$ (Figure $4 b$ ) in $5 / 5$ and $3 / 5$ GBM cell lines, respectively, whereas the levels of $X I A P$, survivin, $B c l-x L$ and $B c l-w$ mRNAs were not affected (Supplementary Figure S4). In agreement with this finding, miR-125b and $\mathrm{Bcl}-2$ were directly correlated at the RNA level in the cohort of TCGA $(P<0.0001$, Supplementary Table $S 1)$. The cell cycle gene $C C N D 1$ was induced in $4 / 5$ cell lines upon transfection with miR-125b precursor (Figure 4c).

Phenotypic analysis of miR-125b transfected cells. Populations of U87 or $\mathrm{LN}-18$ cells overexpressing miR-125b precursor were 1.5-2-times higher in cell number, whereas populations transduced with anti-miR-125b were $25 \%$ lower 3 days post transfection relative to scrambled control (Figure 5a). To assess cell cycle progression, GBM cells were transduced with anti-miR-125b and subsequently treated with nocodazole to induce cell cycle arrest in G2/M.
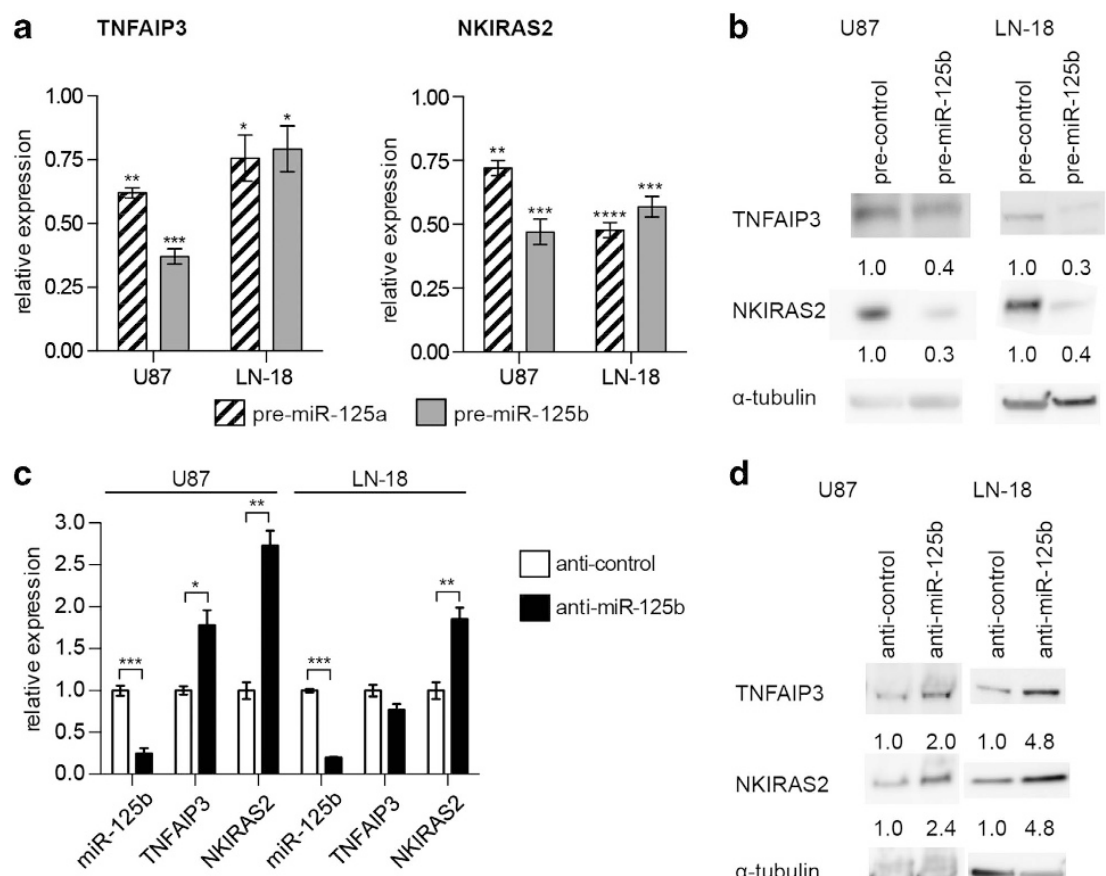

d

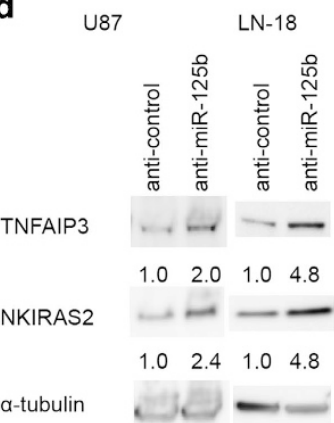

Figure 2 TNFAIP3 and NKIRAS2 are regulated by miR-125a/b. (a) TNFAIP3 or NKIRAS2 mRNA levels by real-time PCR of cells transiently transfected with pre-miR$125 \mathrm{a} / \mathrm{b}$ relative to cells transfected with pre-control $(n=3)$. (b) Western blot of GBM cells transiently transfected with pre-miR-125b relative to pre-control. (c) mRNA levels $(n=3)$ and (d) protein levels of TNFAIP3 and NKIRAS2 in cells lentivirally transduced with anti-miR-125b relative to cells transduced with anti-control 
a

$$
\text { a }
$$
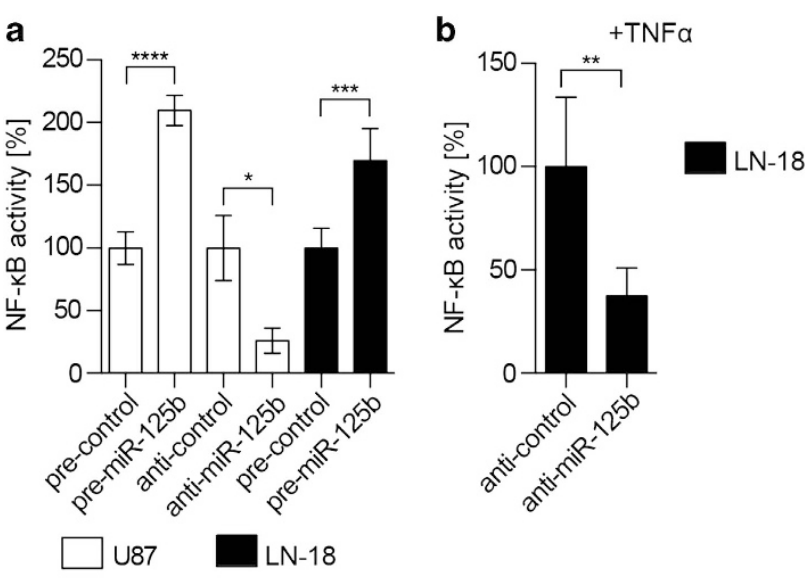

C pre-control pre-miR-125b

TNFa
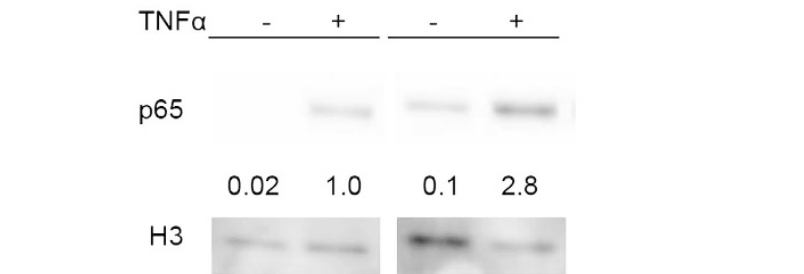

d

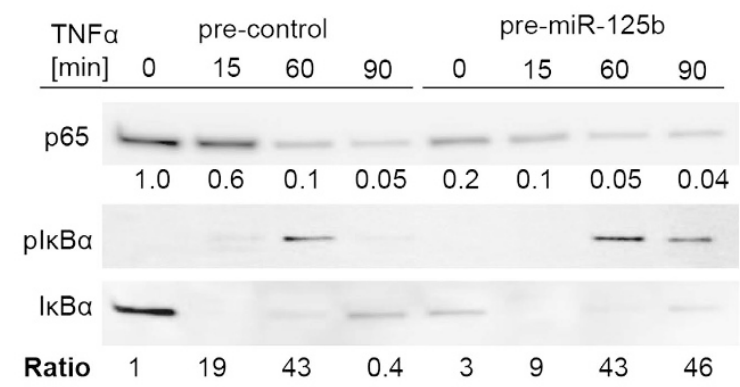

a-tubulin $\longrightarrow-\longrightarrow+-$

Figure 3 miR-125b induces NF- $\kappa$ B activity. (a) NF- $\kappa$ B reporter activity of GBM cells overexpressing miR-125b or anti-miR-125b relative to control cells $(n=6)$. (b) NF- $\kappa$ B reporter activity of $L N-18$ cells overexpressing anti-miR-125b. Cells were induced with $10 \mathrm{ng} / \mathrm{ml} \mathrm{TNF} \alpha$ for $4 \mathrm{~h}$ beginning $20 \mathrm{~h}$ post transfection $(n=6)$. Expression of (c) nuclear p65 and (d) cytoplasmic p65, $I_{\kappa} \mathrm{B} \alpha$ and phospho $\mathrm{I}_{\kappa} \mathrm{B} \alpha$ in LN-18 cells transiently transfected with pre-miR-125b or pre-control by Western blotting. Cells were induced with $10 \mathrm{ng} / \mathrm{ml}$ TNF $\alpha$ beginning at $48 \mathrm{~h}$ post transfection. The ratio of $\mathrm{pl} \kappa \mathrm{B} \alpha$ to $\mathrm{I}_{\kappa} \mathrm{B} \alpha$ protein levels is presented below the corresponding Western blot

In the case of U87 cells transduced with anti-control, $41 \%$ of the population were in G1, whereas $75 \%$ of the cells transduced with anti-miR-125b were in this phase of the cell cycle $(P=0.0033)$, indicating that miR-125b promotes $\mathrm{G} 1$ progression. In contrast, anti-miR-125b had no effect on cell cycle progression of $\mathrm{LN}-18$ cells (Figure $5 \mathrm{~b}$ ).

To assess apoptosis, a caspase 3 cleavage assay was performed. U87 or LN-18 cells overexpressing miR-125b were significantly protected from TNF $\alpha$ or TNF-related inducing ligand (TRAIL)-induced apoptosis (Figure $5 \mathrm{c}$ ). Conversely, experiments performed with cells transduced with anti-miR-125b revealed an increased rate of TNF $\alpha$ induced apoptosis (Figure $5 \mathrm{~d}$ ).
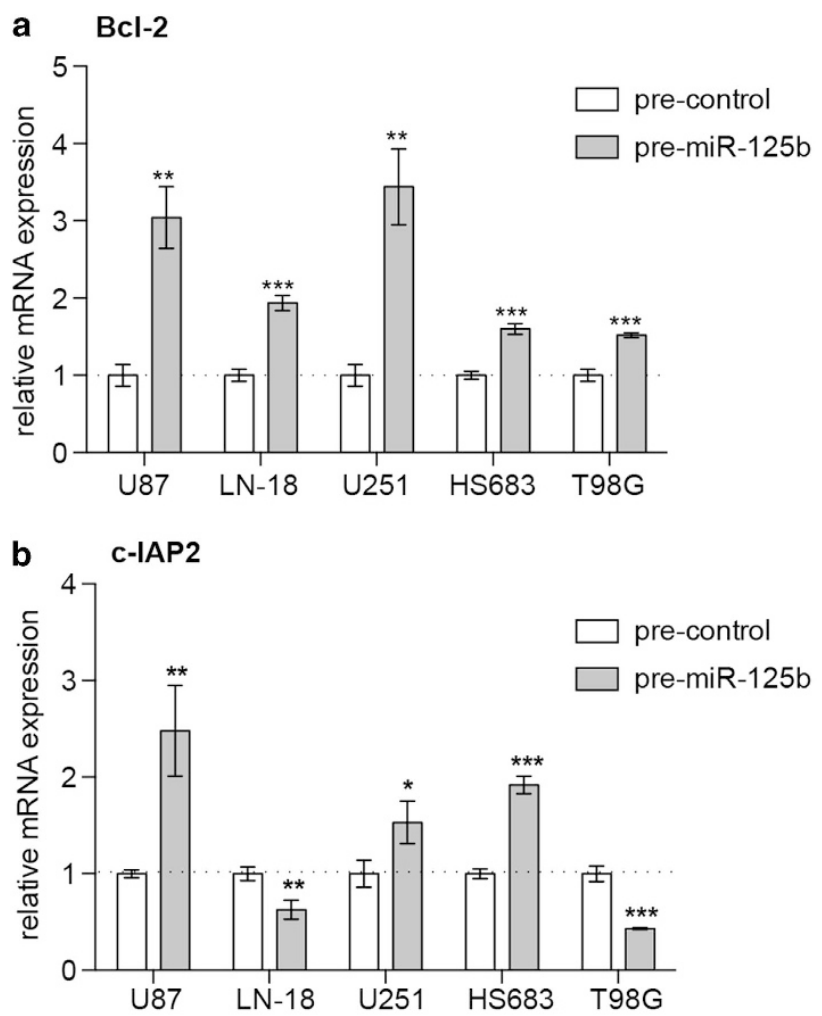

C CCND1

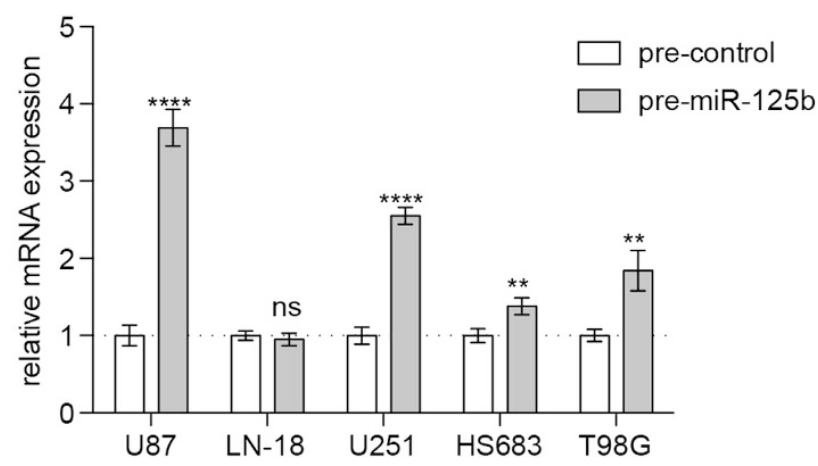

Figure 4 miR-125b induces the expression of NF- $k B$ responsive genes. mRNA levels of $B C l-2(\mathbf{a}), C-I A P 2$ (b) and CCND1 (c) by real-time PCR in GBM cell lines overexpressing miR-125b relative to control transfected cells $(n=3)$

miR-125b induces NF- $\kappa$ B activity by targeting TNFAIP3 and NKIRAS2. miR-125b protects GBM cells from apoptosis, but is this owing to TNFAIP3 and/or NKIRAS2 repression? To address this question, miR-125b-refractory retroviral expression constructs were made containing the coding region of TNFAIP3 or NKIRAS2. Both constructs lack $\mathrm{miR}-125 \mathrm{a} / \mathrm{b}$ target sites in the $3^{\prime}$ UTR, but the TNFAIP3 construct contains a predictive miR-125a/b target site in the coding region which, however, did not affect protein expression (Supplementary Figure S5A). U87 or LN-18 cells transduced with TNFAIP3 or NKIRAS2 expression vectors gave rise to high level expression of the respective gene (Supplementary Figures S5B and C).

$\mathrm{NF}-\kappa \mathrm{B}$ activity was significantly reduced in cells overexpressing TNFAIP3 and NKIRAS2, although this was more 
pronounced in U87 cells than in LN-18 cells (Figure 6a). To assess if ectopic TNFAIP3 or NKIRAS2 can rescue the phenotype obtained with miR-125b, NF- $\kappa$ B activity was
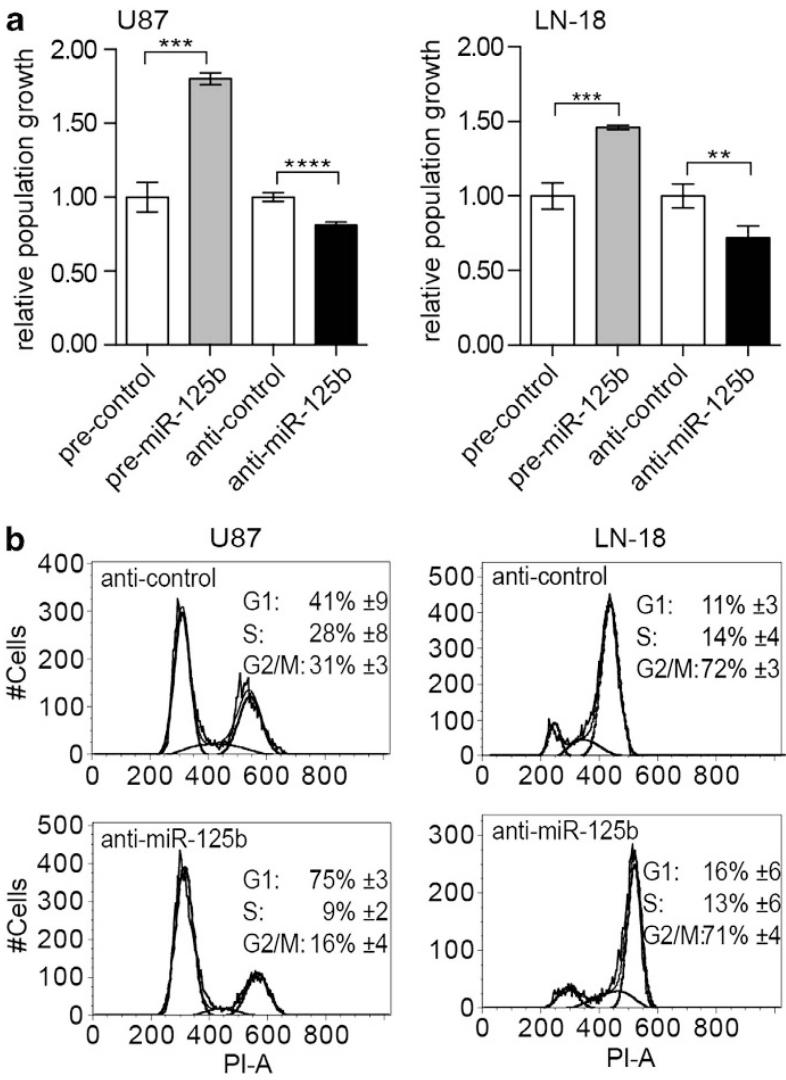

C

U87
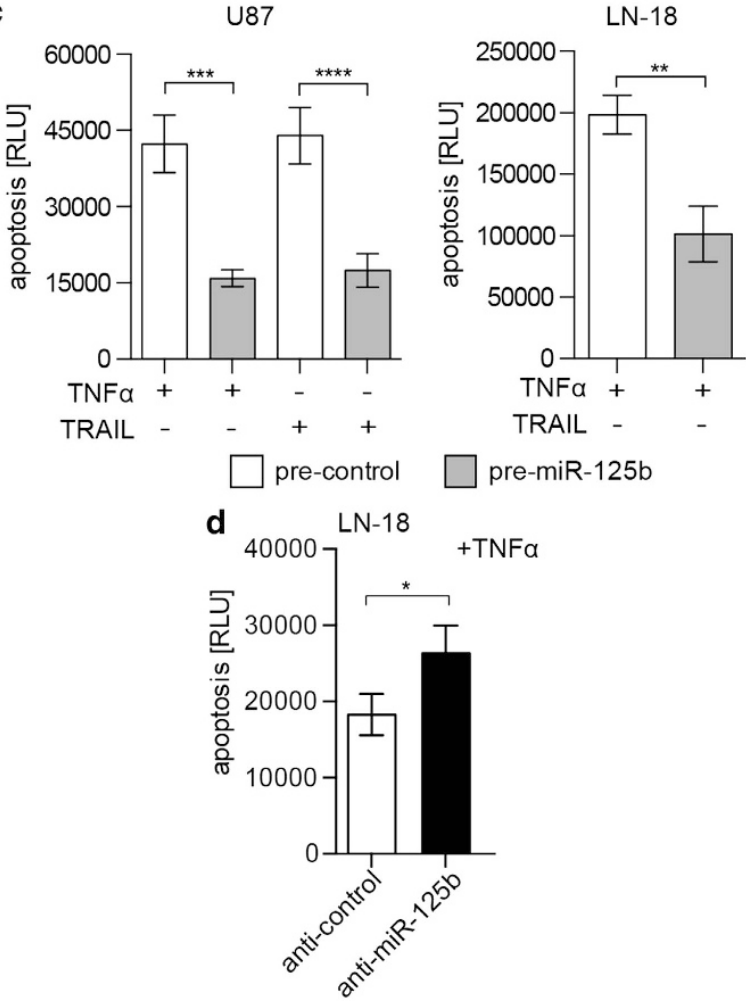

analyzed by luciferase reporter assays. miR-125b elicited a 1.8-fold induction of luciferase activity in U87 cells transduced with control plasmid (pBABE), whereas only a 1.2-1.3-fold induction of luciferase activity was obtained in cells ectopically expressing NKIRAS2 or TNFAIP3 (Figure 6b). Comparable results were also obtained in $\mathrm{LN}-18$ cells giving rise to a 1.5-fold induction in pBABE cells and a 1.2-1.3-fold induction in NKIRAS2 or TNFAIP3 cells, respectively.

In agreement with these results, miR-125b was less efficient in cells ectopically expressing TNFAIP3 or NKIRAS2 than in pBABE control to induce nuclear accumulation of $\mathrm{NF}-\kappa \mathrm{B}$ (Figure $6 \mathrm{c}$, upper panel). In contrast, more NF- $\kappa \mathrm{B}$ was retained in the cytoplasm, whereas less phospho $\mathrm{I}_{\kappa} \mathrm{B}$ was expressed in cells ectopically expressing TNFAIP3 or NKIRAS2 following transfection with miR-125b precursor (Figure 6c, lower panel). In conclusion, these results indicate that ectopic TNFAIP3 or NKIRAS2 can restore miR-125binduced activation of $\mathrm{NF}-\kappa \mathrm{B}$.

Resistance to apoptosis by miR-125b depends on the expression of TNFAIP3 and NKIRAS2. TNF $\alpha$-induced apoptosis was higher in cells ectopically expressing TNFAIP3 or NKIRAS2 compared with pBABE control, consistent with a reduced $\mathrm{NF}-\kappa \mathrm{B}$ activity (Figure $7 \mathrm{a}$ ). However, the ability of miR-125b to protect cells from TNF $\alpha$-induced apoptosis was significantly compromised in cells ectopically expressing TNFAIP3 or NKIRAS2. This was based on the finding that miR-125b elicited a 1.9 times lower apoptosis rate in pBABE control, but only a 1.3-1.4 times lower rate in cells expressing TNFAIP3 or NKIRAS2 compared with cells transfected with pre-control (Figure 7a).

miR-125b confers resistance to $T M Z$ independent of MGMT. Enhanced NF- $\kappa \mathrm{B}$ activity is clearly associated with resistance to $\mathrm{TMZ} .{ }^{23}$ Consistent with this finding, U87 or LN-18 cells transfected with miR-125b precursor were significantly more resistant to $\mathrm{TMZ}$ than cells transfected with pre-control (Figure 7b). Conversely, cells overexpressing anti-miR-125b revealed a higher sensitivity towards TMZ compared with the control (Figure 7c).

To assess if resistance to TMZ by miR-125b depends on the expression of TNFAIP3 or NKIRAS2, retrovirally transduced LN-18 cells were analyzed. Consistent with the results obtained with untransduced cells, pBABE control cells overexpressing miR-125b were significantly more resistant to $\mathrm{TMZ}$ than control transfected cells (compare Figures $7 \mathrm{~b}$ and $\mathrm{d}$ ). In contrast, miR-125b was significantly compromised in its ability to confer resistance to TMZ in LN-18 cells ectopically expressing TNFAIP3. NKIRAS2 proved to be

Figure 5 miR-125b induces proliferation and apoptosis resistance in GBM cells. (a) Population growth of U87 and LN-18 cells overexpressing miR-125b or anti-miR$125 \mathrm{~b}$ relative to the control using the resazurin assay $(n=3)$. (b) Cell cycle analysis of nocodazole-treated cells by flow cytometry $(n=3)$. (c) Apoptosis. Cells were transfected with pre-miR-125b or pre-control and treated with $10 \mathrm{ng} / \mathrm{ml} \mathrm{TNF} \alpha$ or $250 \mathrm{ng} / \mathrm{ml}$ TRAIL for $48 \mathrm{~h}$ beginning $24 \mathrm{~h}$ post transfection. Apoptosis was assessed using the ApoTox-Glo Triplex assay $(n=3)$ (d) LN-18 cells overexpressing antimiR-125b or anti-control were induced with $10 \mathrm{ng} / \mathrm{ml} \mathrm{TNF} \alpha$ for $24 \mathrm{~h}$ and subjected to the ApoTox-Glo Triplex assay $(n=3)$ 
a

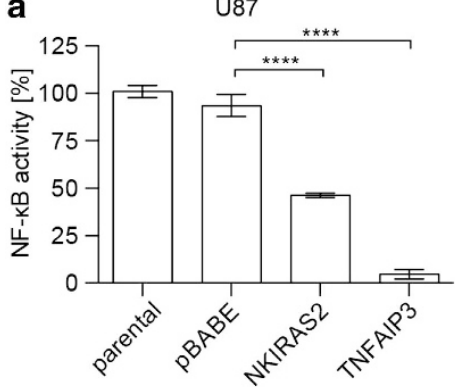

b

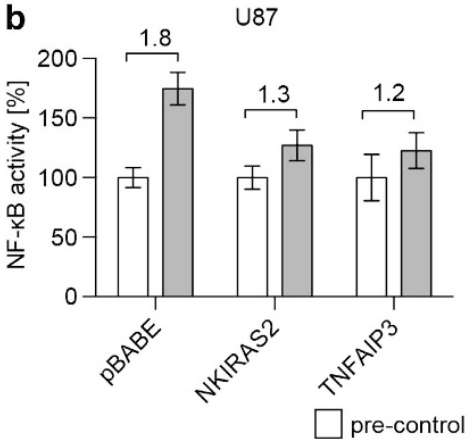

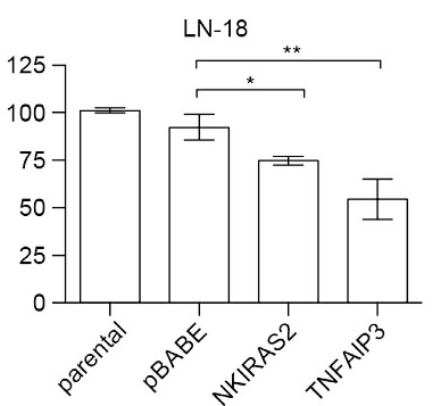

LN-18

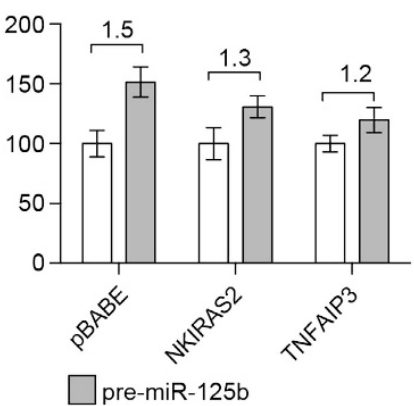

C

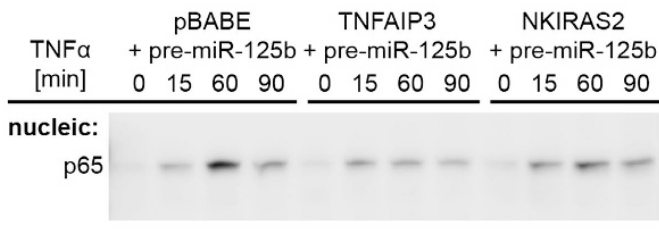

$\begin{array}{lllllllllllll}1.0 & 1.7 & 2.8 & 1.6 & 0.1 & 1.0 & 0.9 & 0.7 & 0.2 & 0.7 & 1.4 & 0.8\end{array}$

H3

cytoplasmic:

p65 $\begin{array}{llllllllllll}1.0 & 0 & 1.4 & 3.8 & 0.9 & 0.7 & 2.0 & 3.4 & 2.6 & 2.7 & 2.3 & 6.8\end{array}$

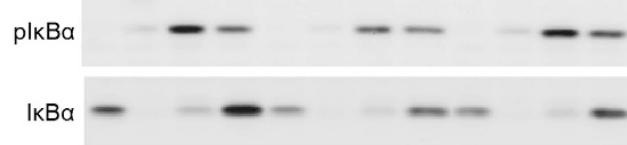

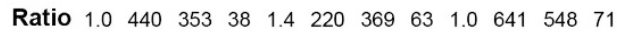
a-tubulin

Figure 6 miR-125b induces NF- $\kappa$ B activity by targeting TNFAIP3 and NKIRAS2. (a) NF- $\kappa$ B activity of GBM cells retrovirally transduced with miR-125b-refractory TNFAIP3, NKIRAS2 or pBABE control relative to untransduced cells $(n=6)$. (b) NF- $\kappa$ B activity of retrovirally transduced cells overexpressing miR-125b relative to pre-control transfected cells $(n=6)$. (c) Western blot analysis of nuclear (upper panel) and cytoplasmic (lower panel) fractions of retrovirally transduced cells overexpressing miR-125b

less efficient than TNFAIP3 to restore miR-125b-induced resistance to TMZ (Figure $7 \mathrm{~d})$.

$\mathrm{NF}-\kappa \mathrm{B}$ is a known transactivator of MGMT. To assess if miR-125b confers TMZ resistance by inducing the expression of MGMT, the steady-state level of MGMT mRNA was analyzed in GBM cell lines overexpressing miR-125b. However, MGMT mRNA levels were unaffected in $4 / 5$ cell lines (Supplementary Figure S6), indicating that miR-125b induces $\mathrm{TMZ}$ resistance independent of MGMT.

miR-125b levels correlate with nuclear NF- $\kappa$ B in the cancer tissue and with the patient's survival. Formalinfixed paraffin-embedded tumor tissues, obtained from a collective of 60 GBM patients, ${ }^{24}$ were analyzed for the expression of miR-125a/b (Supplementary Figure S2). Kaplan-Meier survival curves revealed that miR-125b is an unfavorable prognostic marker for patients treated with TMZ in combination with radiotherapy (Figure 8a upper panel, $P=0.02$, log-rank Mantel-Cox). The median survival for subgroups expressing high levels and low levels of miR-125b was 9 and 18 months, respectively, and the hazard ratio was 0.26 . In contrast, miR-125a was not a predictor of response to TMZ (Figure 8a lower panel, $P=0.14$ ). To validate our collective, all tissues were also analyzed for the MGMT promoter methylation status and IDH1/2 mutation status. Both markers proved to be favorable prognostic markers in this collective (Supplementary Figures S7A and B).

miR-125b expression was not correlated with MGMT methylation or IDH mutation suggesting that miR-125b is an independent prognostic marker (Supplementary Figure S8). To assess if miR-125b affects NF- $\kappa$ B activity in tumor tissues, tissue sections were analyzed by immunohistochemistry using an antibody against p65 (Supplementary Figure S9). Nuclear localization of NF- $\kappa$ B was correlated significantly with miR-125b expression (Figures $8 \mathrm{~b}, P=0.03$ ), indicating that the results obtained in cell lines are also relevant for tumor tissues. Again, no significant correlation was obtained between miR-125a levels and nuclear NF- $\kappa$ B (Figure $8 b$ ).

\section{Discussion}

miR-125b is an 'oncomiR' which plays a central role in molecular dysfunctions linking inflammation with cancer. ${ }^{25}$ It is implicated in proliferation, apoptosis and invasion and is considered to be an important modulator of drug resistance in different tumor systems. ${ }^{26}$ However, controversy exists whether $\mathrm{miR}-125 \mathrm{~b}$ is able to induce or inhibit these processes. Different proapoptotic genes including TP53, Bmf, SIRT1, Bak1 and Puma ${ }^{27-30}$ or anti-apoptotic genes including $\mathrm{Bcl}-2$, Mcl-1, $\mathrm{Bcl}-\mathrm{w}^{31-33}$ were identified as targets of miR-125b. Importantly, these studies often solely relied on data from miR-125b overexpression and did not include rescue experiments to show that the newly identified targets are relevant in miR-125b-mediated cell death or proliferation responses.

In this study, we show that miR-125b induces proliferation and anti-apoptosis by inducing NF- $\kappa$ B activity in GBM cell lines. This is based on the findings that miR-125b induces: (a) activity of a NF- $\kappa \mathrm{B}$ reporter construct, (b) phosphorylation and degradation of $\mathrm{I} \kappa \mathrm{B}$ and, as a consequence, nuclear localization of NF- $\kappa \mathrm{B}$ and (c) expression of known mediators of NF- $\kappa \mathrm{B}$ signaling including Bcl-2, c-IAP2 and CCND1. The results obtained in vitro may be extrapolated to clinical cases of GBM, as miR-125b expression significantly correlates with nuclear NF- $\kappa$ B in surgically obtained GBM samples. 
Furthermore, endogenous levels of miR-125b are sufficient to regulate proliferation and resistance to apoptosis as indicated by anti-miR-125b lentiviral transduction experiments (Figure 5). In agreement with our results, miR-125b was among the top
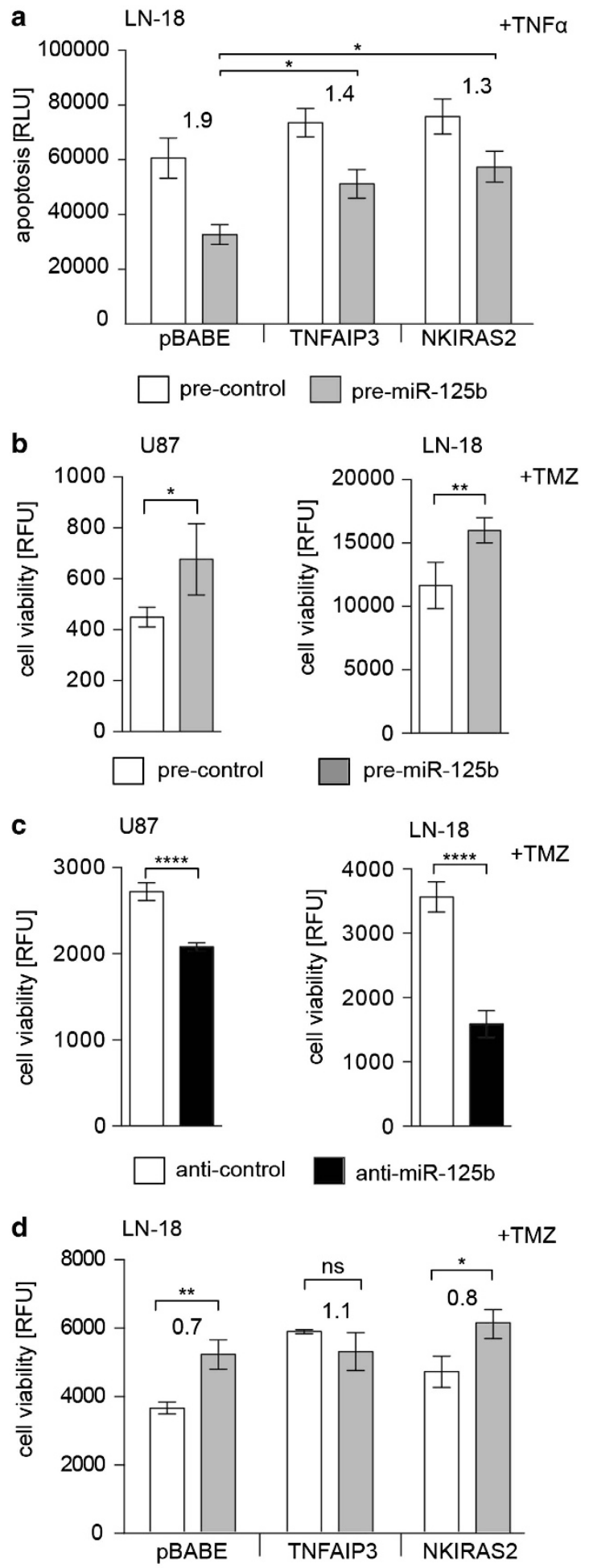

pre-control pre-miR-125b hits in a functional genomics screen for miRNAs regulating $\mathrm{NF}-\kappa \mathrm{B}$ activity in HEK293 cells, ${ }^{34}$ but this was not further investigated. High level expression of $\mathrm{miR}-125 \mathrm{~b}^{35}$ and enhanced $\mathrm{NF}-\kappa \mathrm{B}$ activity ${ }^{8,9}$ are both confined to grade IV (GBM) gliomas suggesting that miR-125b is less important in low grade gliomas.

miR-125b directly targets negative regulators of $N F-\kappa B$ activity including NKIRAS2 and TNFAIP3. Although both miR$125 \mathrm{a}$ and miR-125b were shown recently to control the expression of TNFAIP3 and NF- $\kappa$ B activity in DLBCL, ${ }^{36}$ endogenous levels of miR-125b, but not miR-125a, were sufficient to affect the expression of TNFAIP3 in GBM cells. Thus, the findings obtained in one cell system cannot be extrapolated to another cell system. The finding that TNFAIP3 regulation by miR-125b is particularly important for GBM cells is illustrated by the fact that luciferase activity of a construct containing the miR-125a/b target site from TNFAIP3 was almost maximally reduced by endogenous miR-125b (Figure 1a). Further evidence for TNFAIP3 and NKIRAS2 being relevant targets of miR-125b in GBM cells is based on our findings that NF- $\kappa \mathrm{B}$ activity, anti-apoptosis and $\mathrm{TMZ}$ resistance induced by miR-125b were abrogated in GBM cells ectopically expressing miR-125b-refractory TNFAIP3 or NKIRAS2. The rescue was not complete as TNFAIP3 and NKIRAS2, both of which contribute to NF- $\kappa$ B activity, were not ectopically expressed in the same cell. TNFAIP3 forms part of a negative feedback loop to shut off $N F-\kappa B$ signaling. ${ }^{13,14}$ Both miR- $125 b^{37}$ and TNFAIP3 ${ }^{38}$ are induced by NF- $\kappa$ B activity. In non neoplastic cells, one role of miR-125b may be to modulate NF- $\kappa \mathrm{B}$ activity by counteracting TNFAIP3 induction. In contrast, this negative feedback loop is abrogated in GBM cells owing to overexpression of miR-125b, resulting in prolonged NF- $\kappa \mathrm{B}$ signaling. Consistent with this notion, miR-125b conferred prolonged $\mathrm{I} \kappa \mathrm{B}$ phosphorylation and concomitantly enhanced $\mathrm{l} \kappa \mathrm{B}$ degradation (Figure $3 \mathrm{~d}$ ).

Reduced TNFAIP3 mRNA level in GBM is strongly associated with $T M Z$ resistance, ${ }^{12}$ but the underlying molecular mechanism is largely unknown. We are the first to show that this is at least in part owing to miR-125b. Thus we provide a novel mechanism of TMZ resistance in GBM cells. Consistent with this finding, miR-125b expression in the tumor tissue is significantly correlated with the survival of patients treated with $T M Z$. These findings are important as $\mathrm{TMZ}$ is the major chemotherapeutic agent which is used for the treatment of GBM, but $<40 \%$ of GBM patients initially respond to therapy and resistance develops rapidly. ${ }^{39}$

In addition, we show that NKIRAS2 is directly implicated in apoptosis and contributes to chemosensitivity of GBM tumors (see Figures $7 \mathrm{a}$ and $\mathrm{d}$ ) and, thus, may constitute a new

Figure 7 miR-125b confers resistance to apoptosis and TMZ by targeting TNFAIP3 and NKIRAS2. (a) Retrovirally transduced LN-18 cells were transfected with pre-miR-125b or pre-control and induced with $10 \mathrm{ng} / \mathrm{ml} \mathrm{TNF} \alpha$ for $24 \mathrm{~h}(n=3)$. Apoptosis was assessed using the ApoTox-Glo Triplex assay. (b) Cell viability of GBM cells overexpressing miR-125b in the presence of $200 \mu \mathrm{M}$ TMZ. Cell viability was assessed 3 days after treatment with TMZ using resazurin assay $(n=3)$. (c) Cell viability of GBM cells overexpressing anti-miR-125b or anti-control in the presence of TMZ $(n=6)$. (d) Cell viability of $\mathrm{LN}-18$ cells retrovirally transduced with miR-125b-refractory TNFAIP3, NKIRAS2 or pBABE control following transfection with pre-miR-125b or pre-control in the presence of TMZ $(n=6)$ 

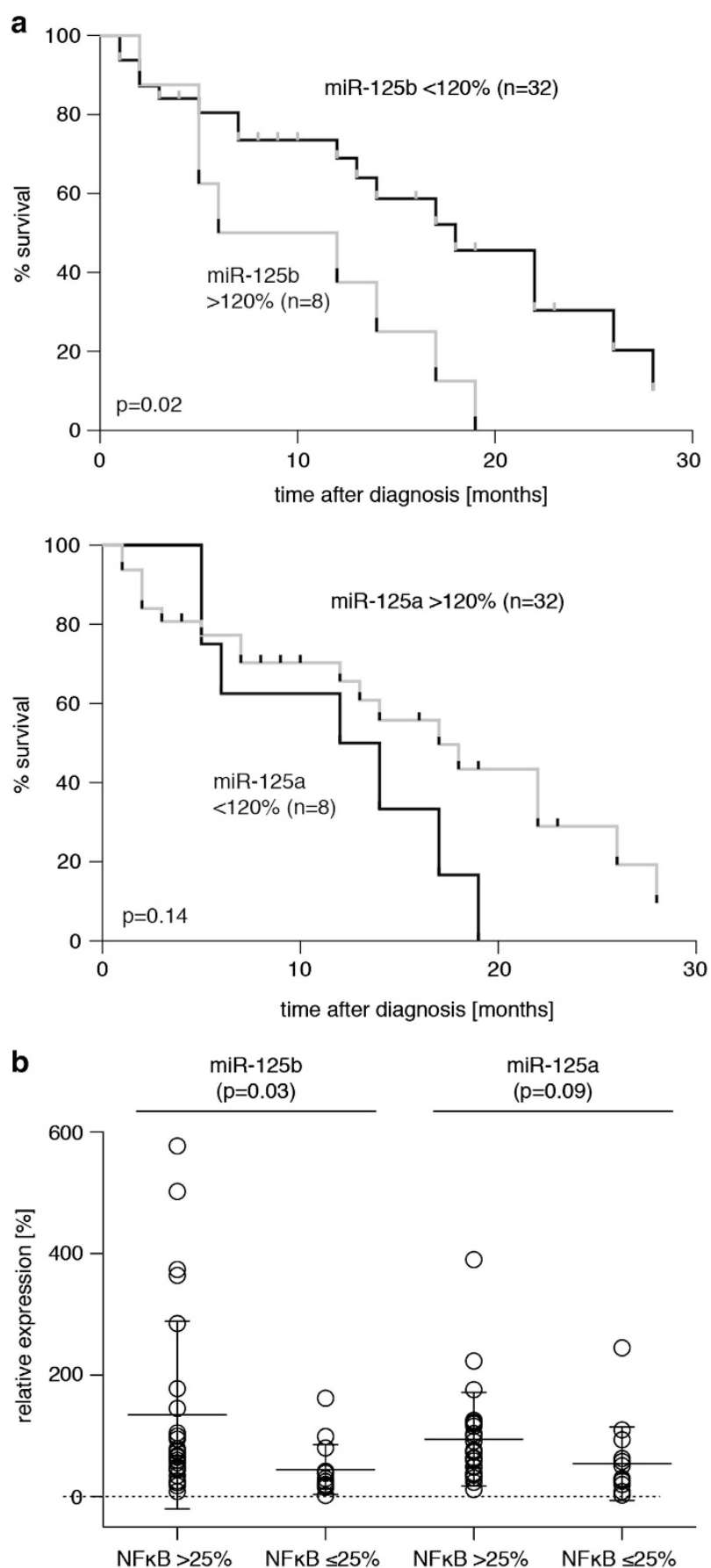

Figure 8 miR-125b expression is directly correlated with NF- $k$ B activity in GBM tissues and with the patient's overall survival. (a) Comparison of the overall survival of patients expressing $>120 \%$ or $<120 \%$ miR-125a/b in the tumor tissue relative with the level of miR-125a/b in U87 cells using Kaplan-Meier survival plots. The threshold was defined using a density blot, which gave rise to a bimodal distribution with best separation at $120 \%$. All patients were treated with TMZ. Significance of correlation was assessed using log-rank (Mantel-Cox) test. (b) Correlation of miR-125a/b expression and nuclear p65 in GBM tissues. A tumor with $>25 \%$ nuclear p65 was considered as constitutive active for NF- $\kappa B^{48}$

chemoresistance marker. NKIRAS2 was reported to disturb cytokine-induced NF- $\kappa \mathrm{B}$ activation. ${ }^{15,16}$ Consistent with previous findings, ${ }^{16}$ ectopic expression of NKIRAS2 resulted in significantly less NF- $\kappa$ B activity (Figure 6a). Surprisingly, miR-125b was reported to induce rather than reduce the expression of NKIRAS2 in primary human macrophages, ${ }^{40}$ but the molecular mechanism was not further investigated. We are the first to show that NKIRAS2 is not only a direct, but also a relevant target of miR-125b in GBM cells.

miR-125b-induced TMZ resistance was independent of TP53. This was indicated by the fact that although LN-18, T98G, HS683 and U251 cells carry mutations or deletions in the TP53 gene, ${ }^{41,42} \mathrm{miR}-125 \mathrm{~b}$ was capable of inducing Bcl-2 expression and protecting these cells from apoptosis to an extent similar to that of TP53 proficient U87 cells (Supplementary Figure S4). Likewise, miR-125b did not affect the level of MGMT expression in most cell lines. Thus we conclude that miR-125b induces resistance of GBM cells to TMZ independent of MGMT or TP53. In addition, high level expression of miR-125b was not inversely correlated with the presence of IDH mutations or promoter methylation of the MGMT gene in GBM tissues. Thus, miR-125b seems to be an independent predictor of response to TMZ. Interestingly, U87 cells transduced with anti-miR-125b were considerably less resistant to $T M Z$ than anti-miR-125b transduced $L N-18$ cells, which might be because of the fact that anti-miR-125b induces cell cycle arrest in $\mathrm{G} 1 / \mathrm{GO}$ in the former.

In conclusion, our results indicate that miR-125b is an important regulator of NF- $\kappa \mathrm{B}$ activity by targeting TNFAIP3 and NKIRAS2 and, thereby, affects proliferation, apoptosis and resistance to TMZ. The finding that $m i R-125 b$ is a predictor of response to $\mathrm{TMZ}$ in GBM patients underlies the importance of miR-125b in NF- $\kappa$ B mediated processes. Our results suggest that miR-125b represents an interesting target for adjuvant therapy as blocking miR-125b by antagomiRs would allow us to modulate the activity of $\mathrm{NF}-\kappa \mathrm{B}$ in $\mathrm{GBM}$ tumors.

\section{Materials and Methods}

Cell lines and culture conditions. The human GBM cell line U87 MG, LN-18, U251, HS683 and T98G were obtained from the American Type Culture Collection (ATCC, Manassas, VA, USA). Cells were cultured in Iscove's modified Dublecco's medium (Sigma-Aldrich, Buchs, Switzerland) supplemented with $2 \mathrm{mmol} / / \mathrm{L}$-alanyl-L-glutamine, $1 \%$ penicillin/streptomycin and $5-10 \%$ fetal bovine serum (Sigma-Aldrich) at $37^{\circ} \mathrm{C}$ and $5 \% \mathrm{CO}_{2}$.

Constructs. Luciferase constructs containing wild-type or mutated miR-125a/b target sites from TNFAIP3 (BC114480) and NKIRAS2 (NM_001001349), respectively, were obtained by cloning double-stranded oligonucleotides into an Xbal site downstream of the luciferase gene of pcDNA3.0_luc. ${ }^{43}$ The coding region of NKIRAS2 was amplified from genomic DNA using the primer pair NKIRAS2 fw and NKIRAS2_rv and cloned between the BamHI and Xhol sites of pBABE-puro (Addgene, Cambridge, MA, USA). A fragment encompassing the $5^{\prime}$ end of TNFAIP3 was amplified from genomic DNA using the primer pair TNFAIP3-5' fw and TNFAIP3-5' $5^{\prime} \mathrm{r}$ and released by cleavage with BgIl and Hindlll. A fragment containing the $3^{\prime}$ end of TNFAIP 3 was released from pEGFRC1-A2O (Addgene) by cleavage with Hindlll and Xhol. Both fragments were cloned between the BamHI and Xhol sites of pBABE-puro to give rise to pBABETNFAIP3. Primers used for cloning are indicated in Supplementary Table S2.

Transfection. Transfection was performed using Effectene, HiPerFect or Attractene reagents (Qiagen, Hombrechtikon, Switzerland) essentially as described $^{43}$ except that $37.5 \mathrm{nM}$ miRNA precursor hsa-miR-125a-5p and hsamiR-125b-5p, pre-miR negative control \#1 (Ambion, Carisbad, CA, USA) was used for transfection. Luciferase constructs and pGl4.32 reporter plasmid (Promega AG, Dübendorf, Switzerland) were used at $1 \mu \mathrm{g} / \mathrm{ml}$ and pRI-SV40 (Promega) was used at $50 \mathrm{ng} / \mathrm{ml}$ transfection mix, respectively. 
Lentiviral and retroviral transduction. U87 and LN-18 cells were transduced with a lentiviral expression vector for antisense hsa-miR-125b-1 (MZIP125b-PA-1) or scrambled control (System Bioscience, Mountain View, CA, USA). Lentiviruses were produced as described. ${ }^{44}$ Cells were analyzed 3 days post transduction. For ectopic expression of miR-125b-refractory TNFAIP3 and NKIRAS2, U87 and LN-18 cells were transduced with pBABE-puro retrovirus (Addgene) as described. ${ }^{45}$ Retrovirally transduced U87 and LN-18 cells were selected with $0.8 \mu \mathrm{g} / \mathrm{ml}$ and $1.5 \mu \mathrm{g} / \mathrm{ml}$ puromycin, respectively.

Luciferase activity assays, cell cycle analysis, apoptosis assay and cell viability assay. NF- $\kappa \mathrm{B}$ reporter assays and luciferase activity assays for target validation were carried out 30 and $48 \mathrm{~h}$ post transfection, respectively, using a dual luciferase reporter assay (Promega) and an Infinite 200 reader (Tecan, Maennedorf, Switzerland).

Cell cycle analysis was performed essentially as described previously. ${ }^{46}$ Lentivirally transduced cells were treated with $80 \mathrm{ng} / \mathrm{ml}$ nocodazole for $16 \mathrm{~h}$ beginning at 3 days post transduction. Flow cytometry was performed using a LSR flow cytometer (Becton Dickinson, Allschwil, Switzerland) and FlowJo software Version 9.5.3 (Tree Star, Ashland, OR, USA).

Apoptosis and viability were assessed using the ApoTox-Glo Triplex assay (Promega). Apoptosis was induced by treating the cells with $10 \mathrm{ng} / \mathrm{ml}$ TNF $\alpha$ (PeproTech, Rocky Hill, NJ, USA) or $250 \mathrm{ng} / \mathrm{ml}$ TRAIL (R\&D Systems, Oxon, UK). Cells were analyzed $24-48 \mathrm{~h}$ following stimulation.

TMZ (Sigma-Aldrich) sensitivity was assessed using the metabolic resazurin assay (Sigma-Aldrich) in cells cultured in the presence of TMZ for 3 days.

RNA isolation and Real-time PCR. RNA extraction and real-time PCR was performed as described in. ${ }^{43}$ Quantitative PCR of anti-apoptotic markers was carried out using Quantitect primers (Qiagen); all other amplifications were done using TaqMan assay (Applied Biosystems, Rotkreuz, Switzerland). Quantitative PCR was performed using the one-step PCR system (Applied Biosystems). The mean $C_{T}$ was determined from triplicate experiments. miRNA and mRNA levels were normalized to the level obtained for RNU48 and GAPDH, respectively. Changes in expression were calculated using the $\Delta \Delta \mathrm{C}_{\mathrm{T}}$ method.

Cell fractionation and western blot analysis. Cell fractionation was performed using the nuclear extract kit according to the manufacturer's instruction (Active Motif, Carisbad, CA, USA). Protein concentrations were determined using the Pierce BCA assay (Thermo Scientific, Reinach, Switzerland); $5 \mu$ g were loaded per lane on a 4-20\% Mini-PROTEAN TGX Gel (Bio-Rad Laboratories AG, Reinach, Switzerland). Separated proteins were transferred to PVDF membranes using the transfer turbo blot system (Bio-Rad). Monoclonal antibodies used in this study were directed against TNFAIP3 (clone 59A426, diluted 1:100, Abcam, Cambridge, UK), NKIRAS2 (clone ab57303, diluted 1:500, Abcam), $\mid \kappa \mathrm{B} \alpha$ (clone E130, diluted 1:10000, Abcam), phospho- $1 \kappa \mathrm{B} \alpha$ (clone 5A5, diluted 1:2000, Cell Signaling, Beverly, MA, USA), $\alpha$-tubulin (clone B512, diluted 1:2000, SigmaAldrich), histone $3 \mathrm{H} 3$ (clone D1H2, diluted 1:2000, Cell Signaling) and p65 (polyclonal, diluted 1:2000, Abcam). Secondary goat anti-mouse-HRP and goat anti-rabbit HRP antibodies (Bio-Rad) were used at 1:5000 or 1:7000, respectively. Protein levels from total or cytoplasmic extracts were normalized to $\alpha$-tubulin and protein levels from nuclear extracts were normalized to histone 3 . Quantification of protein bands were performed using a luminescent image analyzer LAS-4000 (Fujifilm, Dielsdorf, Switzerland) and Multi Gauge software (Fujifilm Version 3.0).

Immunohistochemistry. For immunohistochemistry, $3-\mu \mathrm{m}$ formalin-fixed paraffin-embedded sections were treated with $25 \mathrm{mM}$ citrate buffer, $\mathrm{pH} 6$, in a pressure cooker essentially as described. ${ }^{47}$ Anti-p65 (Abcam) was used at a 1:50 dilution. Mouse IgG1 (1:20, Dako, Glostrup, Denmark) was used as a negative control. Sections were incubated with EnVision + system (labeled polymer HRP anti-mouse, Dako) for $30 \mathrm{~min}$ at room temperature, visualized with $3,3^{\prime}$-Diaminobenzidin (Sigma-Aldrich) for 8 min and counterstained with haematoxylin.

Laser capture microdissection, IDH1/2 mutation analysis and MGMT promoter methylation analysis. Formalin-fixed paraffinembedded tissues from 58 surgical GBM samples were used for miRNA expression, NF- $\kappa \mathrm{B}, \mathrm{MGMT}$ and IDH1/2 analysis. Clinical characteristics of the patient's collective are described elsewhere. ${ }^{24}$ Tumor tissue was collected by laser capture microdissection as described. ${ }^{43}$ All experiments using human specimens were done in compliance with the ethical guidelines of the Institute of Pathology, University of Bern, and were reviewed by the institutional review board.

Statistics. Statistical analyzes were performed and Kaplan-Meier plots were generated using the GraphPAD prism software (La Jolla, CA, USA). Statistical differences were calculated using unpaired two-tailed Student's $t$-test. A probability of $p \leq 0.05$ was considered statistically significant. Ns, not significant; ${ }^{*} P<0.05$; ${ }^{* *} P<0.01 ;{ }^{* * *} P<0.001 ;{ }^{* * *} P<0.0001$

\section{Conflict of Interest}

The authors declare no conflict of interest.

Acknowledgements. We thank B Wyder for introduction into flow cytometry, A Schläfli and D Shan for help with viruses, M Güdel for immunohistochemistry, $\mathrm{C}$ Schlup for help with pyrosequencing, and N Bandi and Ph Krebs for protocols and helpful discussions. This work was supported by a grant from the Swiss National Science Foundation \#138129 and a grant from the Bernese Cancer League to EV.

1. Louis DN, Ohgaki H, Wiestler OD, Cavenee WK, Burger PC, Jouvet A et al. The 2007 WHO classification of tumours of the central nervous system. Acta Neuropathol 2007; 114: 97-109.

2. Mitchell PP, Ellison DWD. Mendelow ADA. Surgery for malignant gliomas: mechanistic reasoning and slippery statistics. Lancet Neurol 2005; 4: 10-10.

3. Stupp R, Hegi ME, Mason WP, van den Bent MJ, Taphoorn MJB, Janzer RC et al. Effects of radiotherapy with concomitant and adjuvant temozolomide versus radiotherapy alone on survival in glioblastoma in a randomised phase III study: 5-year analysis of the EORTC-NCIC trial. Lancet Oncol 2009; 10: 459-466.

4. Esteller M, Garcia-Foncillas J, Andion E, Goodman SN, Hidalgo OF, Vanaclocha V et al. Inactivation of the DNA-repair gene MGMT and the clinical response of gliomas to alkylating agents. N Engl J Med 2000; 343: 1350-1354.

5. Hegi ME, Diserens A-C, Gorlia T, Hamou M-F, de Tribolet N, Weller M et al. MGMT gene silencing and benefit from temozolomide in glioblastoma. N Engl J Med 2005; 352: $997-1003$.

6. Parsons DW, Jones S, Zhang X, JC-H Lin, Leary RJ, Angenendt P et al. An integrated genomic analysis of human glioblastoma multiforme. Science 2008; 321: 1807-1812.

7. SongTao QQ, Lei YY, Si GG, YanQing DD, HuiXia HH, XueLin ZZ et al. IDH mutations predict longer survival and response to temozolomide in secondary glioblastoma. Cancer Sci 2012; 103: 269-273.

8. Weaver KD, Yeyeodu S, Cusack JC, Baldwin AS, Ewend MG. Potentiation of chemotherapeutic agents following antagonism of nuclear factor kappa $B$ in human gliomas. J Neurooncol 2003; 61: 187-196.

9. Nagai S, Washiyama K, Kurimoto M, Takaku A, Endo S, Kumanishi T. Aberrant nuclear factor-kappaB activity and its participation in the growth of human malignant astrocytoma. J Neurosurg 2002; 96: 909-917.

10. Wang CYC, Cusack JCJ, Liu RR, Baldwin ASA. Control of inducible chemoresistance: enhanced anti-tumor therapy through increased apoptosis by inhibition of NF-kappaB. Nat Med 1999; 5: 412-417.

11. Nakanishi C, Toi M. Nuclear factor-kappaB inhibitors as sensitizers to anticancer drugs. Nat Rev Cancer 2005; 5: 297-309.

12. Bredel M, Bredel C, Juric D, Duran GE, Yu RX, Harsh GR et al. Tumor necrosis factor-alpha-induced protein 3 as a putative regulator of nuclear factor-kappaB-mediated resistance to O6-alkylating agents in human glioblastomas. J Clin Oncol 2006; 24 : 274-287.

13. Shembade N, Ma A, Harhaj EW. Inhibition of NF-kappaB signaling by A20 through disruption of ubiquitin enzyme complexes. Science 2010; 327: 1135-1139.

14. Hymowitz SG, Wertz IE. A20: from ubiquitin editing to tumour suppression. Nat Rev Cancer 2010; 10: 332-341.

15. Fenwick $\mathrm{C}$, Na SY, Voll RE, Zhong H, Im SY, Lee JW et al. A subclass of Ras proteins that regulate the degradation of IkappaB. Science 2000; 287: 869-873.

16. Tago K, Funakoshi-Tago M, Sakinawa M, Mizuno N, Itoh H. KappaB-Ras is a nuclearcytoplasmic small GTPase that inhibits NF-kappaB activation through the suppression of transcriptional activation of p65/RelA. J Biol Chem 2010; 285: 30622-30633.

17. Lin $H$, Wang $Y$, Zhang $X$, Liu B, Zhang $W$, Cheng J. Prognostic significance of kappaB-Ras1 expression in gliomas. Med Oncology 2012; 29: 1272-1279.

18. Chen Y, Vallee S, Wu J, Vu D, Sondek J, Ghosh G. Inhibition of NF-kappaB activity by IkappaBbeta in association with kappaB-Ras. Mol Cell Biol 2004; 24: 3048-3056.

19. Iorio MV, Croce CM. MicroRNA dysregulation in cancer: diagnostics, monitoring and therapeutics. A comprehensive review. EMBO Mol Med 2012; 4: 143-159.

20. Hwang H-WH, Mendell JTJ. MicroRNAs in cell proliferation, cell death, and tumorigenesis. Br J Cancer 2006; 94: 776-780

21. Shi L, Zhang J, Pan T, Zhou J, Gong W, Liu N et al. MiR-125b is critical for the suppression of human U251 glioma stem cell proliferation. Brain Res 2010; 1312: 120-126. 
22. Yu Y, Wan Y, Huang C. The biological functions of NF-kappaB1 (p50) and its potential as an anti-cancer target. Curr Cancer Drug Targets 2009; 9: 566-571.

23. Lavon I, Fuchs D, Zrihan D, Efroni G, Zelikovitch B, Fellig $Y$ et al. Novel mechanism whereby nuclear factor kappaB mediates DNA damage repair through regulation of O(6)-methylguanine-DNA-methyltransferase. Cancer Res 2007; 67: 8952-8959.

24. Vassella E, Vajtai I, Bandi N, Arnold M, Kocher V, Mariani L. Primer extension based quantitative polymerase chain reaction reveals consistent differences in the methylation status of the MGMT promoter in diffusely infiltrating gliomas (WHO grade II-IV) of adults. J Neurooncol 2011; 104: 293-303.

25. Tili E, Michaille J-J, Croce CM. MicroRNAs play a central role in molecular dysfunctions linking inflammation with cancer. Immunol Rev 2013; 253: 167-184.

26. Sun $Y-M$, Lin $K-Y$, Chen $Y-Q$. Diverse functions of miR-125 family in different cell contexts. J Hematol Oncol 2013; 6: 6.

27. Zhang Y, Gao J-S, Tang X, Tucker LD, Quesenberry P, Rigoutsos I et al. MicroRNA 125a and its regulation of the $\mathrm{p} 53$ tumor suppressor gene. FEBS Lett 2009; 583: 3725-3730.

28. Xia H-F, He T-Z, Liu C-M, Cui Y, Song P-P, Jin X-H et al. MiR-125b expression affects the proliferation and apoptosis of human glioma cells by targeting Bmf. Cell Physiol Biochem 2009; 23: 347-358.

29. Murray MY, Rushworth SA, Zaitseva L, Bowles KM, Macewan DJ. Attenuation of dexamethasone-induced cell death in multiple myeloma is mediated by miR-125b expression. Cell Cycle 2013; 12: 2144-2153.

30. Shi X-B, Xue L, Yang J, Ma A-H, Zhao J, Xu M et al. An androgen-regulated miRNA suppresses Bak1 expression and induces androgen-independent growth of prostate cancer cells. Proc Natl Acad Sci USA 2007; 104: 19983-19988.

31. Gong J, Zhang J-P, Li B, Zeng C, You K, Chen M-X et al. MicroRNA-125b promotes apoptosis by regulating the expression of Mcl-1 Bcl-w and IL-6R. Oncogene 2013; 32 3071-3079.

32. Willimott S, Wagner SD. miR-125b and miR-155 contribute to BCL2 repression and proliferation in response to CD40 ligand (CD154) in human leukemic B-cells. J Biol Chem 2012; 287: 2608-2617.

33. Zhao A, Zeng Q, Xie X, Zhou J, Yue W, Li Y et al. MicroRNA-125b induces cancer cell apoptosis through suppression of Bcl-2 expression. J Genet Genomics 2012; 39: 29-35.

34. Olarerin-George AO, Anton L, Hwang Y-C, Elovitz MA, Hogenesch JB. A functional genomics screen for microRNA regulators of NF-kappaB signaling. BMC Biol 2013; 11: 19-16.

35. Wu N, Lin X, Zhao X, Zheng L, Xiao L, Liu J et al. MiR-125b acts as an oncogene in glioblastoma cells and inhibits cell apoptosis through p53 and p38MAPK-independent pathways. Br J Cancer 2013; 109: 2853-2863.

36. Kim S-W, Ramasamy K, Bouamar H, Lin A-P, Jiang D, Aguiar RCT. MicroRNAs miR-125a and $\mathrm{miR}-125 \mathrm{~b}$ constitutively activate the NF- $\kappa \mathrm{B}$ pathway by targeting the tumor necrosis factor alpha-induced protein 3 (TNFAIP3, A20). Proc Natl Acad Sci USA 2012; 109: 7865-7870.

37. Tan G, Niu J, Shi Y, Ouyang H, Wu Z-H. NF- $\kappa$ B-dependent microRNA-125b up-regulation promotes cell survival by targeting p38 $\alpha$ upon ultraviolet radiation. J Biol Chem 2012; 287: 33036-33047.

38. Verstrepen L, Verhelst K, van Loo G, Carpentier I, Ley SC, Beyaert R. Expression, biological activities and mechanisms of action of A20 (TNFAIP3). Biochem Pharmacol 2010; 80: 2009-2020.
39. Stupp R, Hegi ME, Gilbert MR, Chakravarti A. Chemoradiotherapy in malignant glioma: standard of care and future directions. J Clin Oncol 2007; 25: 4127-4136.

40. Murphy AJ, Guyre PM, Pioli PA. Estradiol suppresses NF-kappa B activation through coordinated regulation of let-7a and miR-125b in primary human macrophages. J Immunol 2010; 184: 5029-5037.

41. Ishii N, Maier D, Merlo A, Tada M, Sawamura Y, Diserens AC et al. Frequent co-alterations of TP53, p16/CDKN2A, p14ARF, PTEN tumor suppressor genes in human glioma cell lines. Brain Pathol 1999; 9: 469-479.

42. Wischhusen J, Naumann U, Ohgaki H, Rastinejad F, Weller M. CP-31398 a novel p53-stabilizing agent, induces p53-dependent and p53-independent glioma cell death. Oncogene 2003; 22: 8233-8245

43. Bandi N, Zbinden S, Gugger M, Arnold M, Kocher V, Hasan L et al. miR-15a and miR-16 are implicated in cell cycle regulation in a Rb-dependent manner and are frequently deleted or down-regulated in non-small cell lung cancer. Cancer Res 2009; 69: 5553-5559.

44. Britschgi C, Jenal M, Rizzi M, Mueller BU, Torbett BE, Andres A-C et al. HIC1 tumour suppressor gene is suppressed in acute myeloid leukaemia and induced during granulocytic differentiation. Br J Haematol 2008; 141: 179-187.

45. Gautschi O, Tepper CG, Purnell PR, Izumiya Y, Evans CP, Green TP et al. Regulation of Id1 expression by SRC: implications for targeting of the bone morphogenetic protein pathway in cancer. Cancer Res 2008; 68: 2250-2258.

46. Linsley PSP, Schelter JJ, Burchard JJ, Kibukawa MM, Martin MMM, Bartz SRS et al. Transcripts targeted by the microRNA-16 family cooperatively regulate cell cycle progression. Mol Cell Biol 2007; 27: 2240-2252.

47. Gugger MM, Kappeler AA, Vonlanthen SS, Altermatt HJH, Ris HBH, Lardinois DD et al. Alterations of cell cycle regulators are less frequent in advanced non-small cell lung cancer than in resectable tumours. Lung Cancer 2001; 33: 229-239.

48. Korkolopoulou P, Levidou G, Saetta AA, El-Habr E, Eftichiadis C, Demenagas P et al. Expression of nuclear factor- $\kappa \mathrm{B}$ in human astrocytomas: relation to $\mathrm{pl \kappa Ba}$, vascular endothelial growth factor, Cox-2, microvascular characteristics, and survival. Hum Pathol 2008; 39: 1143-1152.

(c) (i) (2) Cell Death and Disease is an open-access journal published by Nature Publishing Group. This work is licensed under a Creative Commons Attribution-NonCommercialShareAlike 3.0 Unported License. The images or other third party material in this article are included in the article's Creative Commons license, unless indicated otherwise in the credit line; if the material is not included under the Creative Commons license, users will need to obtain permission from the license holder to reproduce the material. To view a copy of this license, visit http://creativecommons.org/ licenses/by-nc-sa/3.0/

Supplementary Information accompanies this paper on Cell Death and Disease website (http://www.nature.com/cddis) 